\author{
Marquette University \\ e-Publications@Marquette
}

7-26-2006

\title{
Polyethylene and Polypropylene Nanocomposites Based on Polymerically - Modified Clay Containing Alkylstyrene Units
}

Jinguo Zhang

Marquette University

Charles A. Wilkie

Marquette University, charles.wilkie@marquette.edu

Follow this and additional works at: https://epublications.marquette.edu/chem_fac

Part of the Chemistry Commons

\section{Recommended Citation}

Zhang, Jinguo and Wilkie, Charles A., "Polyethylene and Polypropylene Nanocomposites Based on Polymerically - Modified Clay Containing Alkylstyrene Units" (2006). Chemistry Faculty Research and Publications. 104.

https://epublications.marquette.edu/chem_fac/104 
Marquette University

e-Publications@Marquette

\title{
Chemistry Faculty Research and Publications/College of Arts and Sciences
}

This paper is NOT THE PUBLISHED VERSION; but the author's final, peer-reviewed manuscript. The published version may be accessed by following the link in th citation below.

Polymer, Vol. 47, No. 16 (July 2006): 5736-5743. DOI. This article is C Elsevier and permission has been granted for this version to appear in e-Publications@Marquette. Elsevier does not grant permission for this article to be further copied/distributed or hosted elsewhere without the express permission from Elsevier.

\section{Polyethylene and Polypropylene Nanocomposites Based on Polymerically- Modified Clay Containing Alkylstyrene Units}

\author{
Jinguo Zhang \\ Department of Chemistry, Marquette University, Milwaukee, WI \\ Charles A. Wilkie \\ Department of Chemistry, Marquette University, Milwaukee, WI
}

\section{Abstract}

Sodium montmorillonite was modified with a new polymeric surfactant. The high molecular weight of the surfactant appears to have led to incomplete cation exchange of the clays, but did promote nanocomposite formation with polyethylene and polypropylene. X-ray diffraction combined with transmission electron microscopy revealed a mixed nanocomposite morphology. The thermal stability of the nanocomposites was evaluated by thermogravimetric analysis, while flammability of the nanocomposites was evaluated by cone calorimetry. A significant $40 \%$ reduction in peak heat release rate was observed at $10 \%$ organo-clay (3\% inorganic clay) loading with an even higher $50 \%$ reduction at a loading level of $16 \%$ modified clay (5\% inorganic clay). Despite possible plasticization effects by the polymers used as an organic modification for the clays, the mechanical properties such as Young's modulus and elongation were not severely impacted by the nanocomposite formation. 


\section{Keywords}

Nanocomposites, Polymeric surfactant, Polyethylene

\section{Introduction}

Polymer/clay nanocomposites are of high interest, since low inorganic clay loading levels can lead to

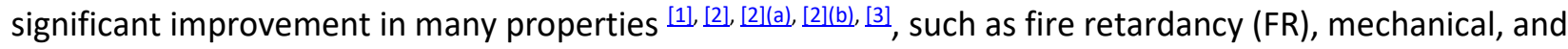
barrier properties. A significant amount of work has been focused on the fire retardancy of polymer/clay nanocomposites $[4],[5],[6]$, as an alternative for, or in addition to, traditional FR-additives. Previous work has shown that 3-10\% organically-modified clay dispersed in the polymer matrix can reduce the heat release rate (HRR) from $30 \%$ to $70 \%$ and it also provides mechanical reinforcement and a non-dripping character to the combustion and the reduction in the peak heat release rate is very polymer dependent. In addition, the synergistic effect between clay and conventional FR-additives permits achieving fire retardancy with a substantially reduced amount of conventional FR-additives [4], [7].

To successfully fabricate polymer/clay nanocomposites, the inherent immiscibility between most organic polymers and the inorganic clay filler must be overcome. Typically, alkyl based quaternary ammonium salts are used to exchange the inorganic cations in the clay galleries, rendering organophilicity to the clay particles [12]. For non-polar polymers, besides the organic modification of the clays with ammonium salts, a polymeric compatibilizer is often required to obtain well-dispersed systems ${ }^{[8],[8](a),[8](b),[9]}$, if the nanocomposites are to be made through melt processing $\frac{[8 a]}{2}$. The normal condition is to use the polyolefin-graft-maleic anhydride as a compatibilizer, since reaction may occur between a properly functionalized surfactant and the maleic anhydride to form the nanocomposite. Thus, one initially prepares a masterbatch containing PP- $g$-MA or PE- $g$ MA together with the clay and then this is combined with the virgin polyolefin to achieve the required clay content.

Recent work from this laboratory showed the successful use of oligomeric surfactants to modify clay by the ion-exchange method [10], [10](a), [10](b), [10](c), [11], [11](a), [11](b), [11](c), [11](d). Generally, the oligomers are random copolymers of vinylbenzyl chloride (VBC) and another monomer, such as styrene, methyl mathacrylate, lauryl acrylate, etc. Cationic surfactants are formed by reacting an amine with benzylchloride. The resulting oligomerically-modified clays contain a much higher organic content than the typical alkyl-ammonium modified clays. These oligomerically-modified clays can be utilized to form nanocomposites with either polar or non-polar polymers. Typically, the $d$-spacing prior to nanocomposite formation is around $4 \mathrm{~nm}$ [12], and polymer chains can intercalate into the clay gallery sometimes without further expansion being required. Most of the nanocomposites based on the oligomerically-modified clays exhibit good nano-dispersion, i.e., either intercalation or delamination.

Oligomerically-modified clays containing lauryl acrylate units [11], [11](a), [11](b), [11](c), [11](d) possess higher thermal stability than the common ammonium-based organically-modified clays and can be processed above $300{ }^{\circ} \mathrm{C}$. Nanocomposites based on these clays can be melt blended in a relatively short time (3-5 min), which may be attractive to industry. Since the oligomerically-modified clay contains a large organic content, a considerable amount of oligomer will inevitably be introduced to the nanocomposite, which can act as a plasticizer for the polymer matrix. Functional groups in the oligomer, such as the ester group in lauryl clay (cf. clay modified by a copolymer of lauryl acrylate and VBC) and triclay ( $c f$. clay modified by a terpolymer of lauryl

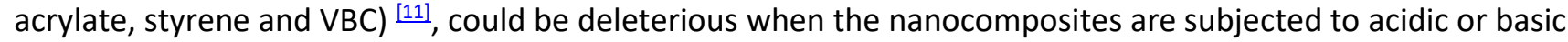
condition. In addition, when the surfactant contains polar moieties, such as carboxy groups, the compatibility with the non-polar polyethylene and polypropylene is not as good as is necessary to achieve good nanodispersion of the clay in the polymer. Among these oligomerically-modified clays, triclay [11], [11](a), [11](b), [11](c), [11](d) exhibited the best reduction in the peak heat release rate (PHRR), as measured by cone calorimetry.

In this work, the ester group has been avoided and, instead, a long alkyl chain was attached to the styrene to determine whether an alkylstyrene surfactant is suitable as an organic modification for clays. In order to reduce any plasticizing effect, a polymeric surfactant, rather than a lower molecular weight oligomer, has been used. This new polymeric surfactant, containing 4-nonylstyrene, was used to modify sodium 
montmorillonite, and was subsequently melt blended with polyethylene (PE) and polypropylene (PP) to prepare nanocomposites.

\section{Experimental}

\subsection{Materials}

Polyethylene (LDPE), Petrothene NA960000, was supplied by Equistar Chemical Company. Isotactic polypropylene (melt index $230^{\circ} \mathrm{C} / 2.16 \mathrm{~kg}, 4 \mathrm{~g} / 10 \mathrm{~min}$ ), vinylbenzyl chloride, 2,2'-azobisisobutyronitrile (AIBN), and lithium wire were acquired from Aldrich Chemical Company. 1-Bromooctane was acquired from Lancaster. Sodium montmorillonite (Na Cloisite, with CEC $\cong 0.95 \mathrm{meq} / \mathrm{g}$ ) was provided by Southern Clay Products, Inc.

\subsection{Synthesis of 4-nonylstyrene}

Lithium wire (1.4 g, 0.20 mol) was placed in a $250 \mathrm{ml}$ three-neck round bottom flask containing $50 \mathrm{ml}$ of dry ether and equipped with an addition funnel. The system was maintained under nitrogen flow and was held at $0{ }^{\circ} \mathrm{C}$ using an ice water bath. A few drops of 1-bromobutane were added and stirred until the lithium metal became bright, $19.3 \mathrm{~g}(0.10 \mathrm{~mol})$ of 1-bromooctane in $100 \mathrm{ml}$ of dry ether was then added drop-wise over a $1 \mathrm{~h}$ period. The ice water bath was removed and the system was allowed to warm to room temperature and was held at that temperature for $30 \mathrm{~min}$. The ether solution of octyllithium was transferred by syringe, drop-wise, to a separate flask containing a solution of $14.5 \mathrm{~g}(0.095 \mathrm{~mol})$ of vinylbenzyl chloride in $100 \mathrm{ml}$ of dry THF. The solution was stirred under nitrogen purge for $1 \mathrm{~h}$, and then $1 \mathrm{M} \mathrm{HCl}$ was added to hydrolyze any remaining lithium reagents. The oil layer was extracted with ether followed by column chromatographic separation (hexane/ethyl acetate 90:10). Colorless 4-nonylstyrene (18.6 g, 81\% yield) was recovered. The identity of the nonylstyrene is clearly established by NMR spectroscopy. ${ }^{1} \mathrm{H} \mathrm{NMR}\left(\mathrm{CDCl}_{3}, \mathrm{ppm}\right): 7.32(\mathrm{~d}, \mathrm{~J}=9 \mathrm{~Hz}, 2 \mathrm{H}, \mathrm{ArH}), 7.15$ (d, $J=9 \mathrm{~Hz}, 2 \mathrm{H}, \operatorname{ArH}), 6.68$ (dd, $J=12,18 \mathrm{~Hz}, 1 \mathrm{H}, \operatorname{ArCH}-), 5.70$ (d, $J=18 \mathrm{~Hz}, 1 \mathrm{H}, \operatorname{ArCHCH}_{2}$ Cis), $5.17(\mathrm{~d}, J=12 \mathrm{~Hz}$, $1 \mathrm{H}, \mathrm{ArCHCH} \mathrm{C}_{2}$ trans), $2.58\left(\mathrm{t}, J=7 \mathrm{~Hz}, 2 \mathrm{H}, \mathrm{ArCH}_{2}-\right), 1.57$ (quintet, $\left.J=7 \mathrm{~Hz}, 2 \mathrm{H}, \mathrm{ArCH}_{2} \mathrm{CH}_{2}-\right), 1.30\left(\mathrm{~m}, 12 \mathrm{H},-\left(\mathrm{CH}_{2}\right)_{6}-\right)$, $0.88\left(\mathrm{t}, \mathrm{J}=6 \mathrm{~Hz}, 3 \mathrm{H},-\mathrm{CH}_{3}\right)$.

\subsection{Copolymer and its ammonium salt}

4-Nonylstyrene $(46 \mathrm{~g}, 0.20 \mathrm{~mol})$ and vinylbenzyl chloride $(3.1 \mathrm{~g}, 0.02 \mathrm{~mol})$ were dissolved in $100 \mathrm{ml}$ of THF in a $250 \mathrm{ml}$ flask. The solution was magnetically stirred for $10 \mathrm{~min}$, and heated to gentle reflux, then $0.32 \mathrm{~g}$ $(2.0 \mathrm{mmol})$ of AIBN was added to initiate the polymerization and the system was maintained at reflux for $12 \mathrm{~h}$. The copolymer was precipitated by pouring the solution into $500 \mathrm{ml}$ of methanol and $45 \mathrm{~g}$ of copolymer were collected after filtration followed by overnight drying in a vacuum oven at $70-80^{\circ} \mathrm{C}$. The molecular weight of the polymer was characterized by gel permeation chromatography; the number average molecular weight is 31,000 with a polymer dispersity index of 3.1. ${ }^{1} \mathrm{H} \mathrm{NMR}\left(\mathrm{CDCl}_{3}, \mathrm{ppm}\right): 7.14(\mathrm{br}, 22 \mathrm{H}, \mathrm{ArH}), 6.72(\mathrm{br}, 22 \mathrm{H}, \mathrm{ArH}), 4.47(\mathrm{br}$, $\left.2 \mathrm{H}, \mathrm{ArCH}_{2} \mathrm{Cl}\right), 2.56\left(\mathrm{br}, 2 \mathrm{H}, \mathrm{ArCH}_{2}-\right), 2.33(\mathrm{br}, 11 \mathrm{H}, \mathrm{ArCH}-), 1.90\left(\mathrm{br}, 22 \mathrm{H}, \mathrm{ArCHCH}_{2}-\right), 1.63\left(\mathrm{br}, 2 \mathrm{OH}, \mathrm{ArCH}_{2} \mathrm{CH}_{2}-\right)$, $1.29\left(\mathrm{br}, 12 \mathrm{OH},-\left(\mathrm{CH}_{2}\right)_{6}-\right), 0.89\left(\mathrm{t}, 30 \mathrm{H},-\mathrm{CH}_{3}\right)$. The NMR data are consistent with a copolymer composition of 10:1 ratio of nonylstyrene to vinylbenzyl chloride.

Copolymer ( $45 \mathrm{~g}$ ) was first dissolved in $200 \mathrm{ml} \mathrm{THF}$ followed by the addition of $4 \mathrm{~g}$ of triethylamine and the mixture was stirred at room temperature for $12 \mathrm{~h}$ before it was slowly poured into $500 \mathrm{ml}$ of methanol. The polymeric surfactant was collected by filtration and dried overnight in a vacuum oven at $80^{\circ} \mathrm{C}$. There was a new broad peak in the ${ }^{1} \mathrm{H}$ NMR spectrum at $3.44 \mathrm{ppm}$, which may be assigned as the methylene group attached to the nitrogen of the ammonium salt, while the methyl group adjacent to the methylene is in the $1.30 \mathrm{ppm}$ region.

\subsection{Clay modification}

Sodium montmorillonite (15 g) was dispersed in $300 \mathrm{ml}$ of THF/ $\mathrm{H}_{2} \mathrm{O}$ (50:50) and stirred magnetically for $8 \mathrm{~h}$, while $35 \mathrm{~g}$ of surfactant was dissolved in $100 \mathrm{ml}$ THF. An $80 \mathrm{ml}$ portion of the surfactant solution was slowly added to the clay suspension and the system was vigorously stirred for $12 \mathrm{~h}$; subsequently, the remaining surfactant solution was added drop-wise until a precipitate appeared. The precipitate was collected and washed with $500 \mathrm{ml} \mathrm{THF} / \mathrm{H}_{2} \mathrm{O}$ (50:50). After drying at $80^{\circ} \mathrm{C}$ under vacuum, $50 \mathrm{~g}$ of polymerically-modified clay was collected for further study. 


\subsection{Nanocomposite formation}

All polymer/clay nanocomposites were prepared by melt-blending in a Brabender Plasticorder at $60 \mathrm{rpm}$ and $185^{\circ} \mathrm{C}$ for $5 \mathrm{~min}$; these are the same conditions that have been used in previous studies with PE and PP nanocomposites [10], [10](a), [10](b), [10]/(c), [11], [11]](a), [11](b), [11]](c), [11]](d). The polymer and the modified clay were charged into the Brabender chamber simultaneously and after $5 \mathrm{~min}$ of blending the mixture was removed from the chamber and allowed to cool to room temperate. Table 1 lists the compositions of the nanocomposites.

Table 1. Composition, mass \%, of polymer/clay nanocomposites

\begin{tabular}{|l|l|l|l|}
\hline No. & Polymer (PE or PP) & Polymerically-modified clay & Inorganic clay loading \\
\hline 1 & 97 & 3 & 1 \\
\hline 2 & 90 & 10 & 3 \\
\hline 3 & 84 & 16 & 5 \\
\hline
\end{tabular}

\subsection{Characterization}

X-ray diffraction (XRD) was carried out on a Rigaku Geiger Flex, 2-circle powder diffractometer with $\mathrm{Cu}$ $\mathrm{K} \alpha$ generator at $50 \mathrm{kV}$ and $20 \mathrm{~mA}$, scanning from 1 to $10^{\circ}$ at a step value of $0.1^{\circ}$. XRD samples were molded into $20 \mathrm{~mm} \times 15 \mathrm{~mm} \times 1 \mathrm{~mm}$ plaques. Bright field TEM images were obtained with a JEOL 1200 EXII microscope operated with an accelerating voltage of $80 \mathrm{kV}$, and equipped with a Tietz F224 digital camera. Thin sections of the nanocomposites were cut from a plaque using a microtome (Leica Ultracut UCT) equipped with a diamond knife; although liquid nitrogen was used prior to microtoming, and multiple sessions of microtoming for each sample were done, all sections obtained were relatively thick (above $500 \mathrm{~nm}$ ) thus limiting the resolution of the TEM. The sections were transferred to carbon-coated copper grids (200 mesh). No heavy metal staining of sections prior to imaging was necessary, since the contrast between the layered silicate and the polymer matrix was sufficient.

Thermogravimetric analysis (TGA) was performed on a SDT 2960 unit, under 60-80 $\mathrm{ml} / \mathrm{min}$ nitrogen flow. The samples were first equilibrated at $100{ }^{\circ} \mathrm{C}$ and then ramped to $600^{\circ} \mathrm{C}$ at a scan rate of $20^{\circ} \mathrm{C} / \mathrm{min}$. Temperatures are reproducible to $\pm 3{ }^{\circ} \mathrm{C}$ while the fraction of non-volatile is repeatable to $\pm 2 \%$. Cone calorimetry was performed on an Atlas CONE-2 according to ASTM E 1354 under a heat flux of $35 \mathrm{~kW} / \mathrm{m}^{2}$. Exhaust flow was set at $24 \mathrm{l} / \mathrm{s}$. The spark was continuous for $10 \mathrm{~s}$ after ignition. Samples for cone calorimetry were prepared by compression molding into $100 \mathrm{~mm} \times 100 \mathrm{~mm} \times 3 \mathrm{~mm}$ plaques. Typically, results from cone calorimetry are reproducible to within $\pm 10 \%[13],[13](a)$, [13](b). Tensile properties were measured using an MTS Alliance RT/5 tensile test machine at a crosshead speed of $50 \mathrm{~mm} / \mathrm{min}$. The reported values are the average of five determinations. Molecular weight was determined using a DAWN EOS MALLS (Wyatt Technologies) coupled with a W-410 RID (Waters Corporation) using Waters Ultrastyragel columns HR4, HR3, HR1 in series; THF was the mobile phase.

\section{Results and discussion}

\subsection{X-ray diffraction}

X-ray diffraction (XRD) patterns of the polymerically-modified clay and its PE nanocomposites are shown in Fig. 1. The modified clay displays a strong peak at $2.4^{\circ}$, which is approximately the same as that seen in oligomerically-modified clays (lauryl clay, triclay) containing a long alkyl chain in the monomer unit [11], [11](a), [11](b), [11]](c), [11]](d), and corresponds to a $d$-spacing of $3.7 \mathrm{~nm}$. There is a very broad feature in the 4-8 $2 \vartheta$ region, which perhaps implies incomplete ion-exchange, possibly due to the high molecular weight of the surfactant. The XRD patterns of the PE and PP nanocomposites are shown in Fig. 2, Fig. 3. PE and PP nanocomposites have similar XRD patterns at all clay loadings. The broad feature in the $4-8^{\circ} 2 \vartheta$ region remains for all the samples, however, the $d_{001}$ diffraction peak from the polymerically-modified clay is substantially weakened, denoting that exfoliation or disordering of the clay may have occurred. Thus, the XRD traces suggest that the system contains both an immiscible component (from the broad feature at $4-8^{\circ}$ ) and a nano-dispersed component. 


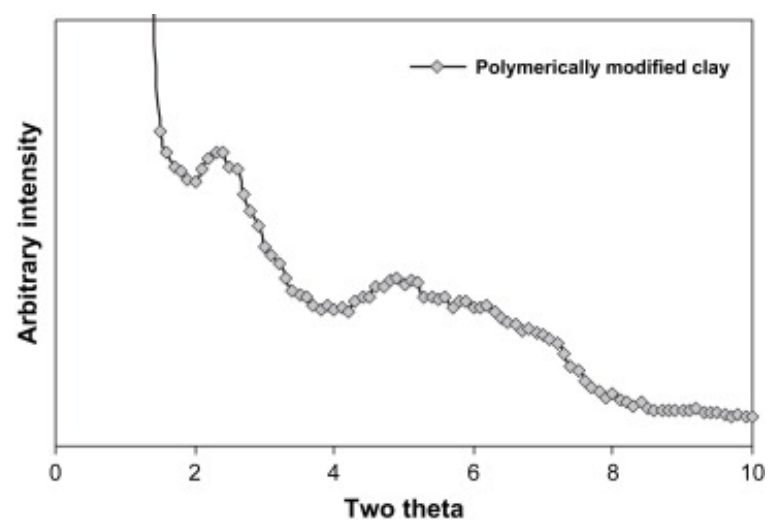

Fig. 1. XRD pattern of polymerically-modified clay.

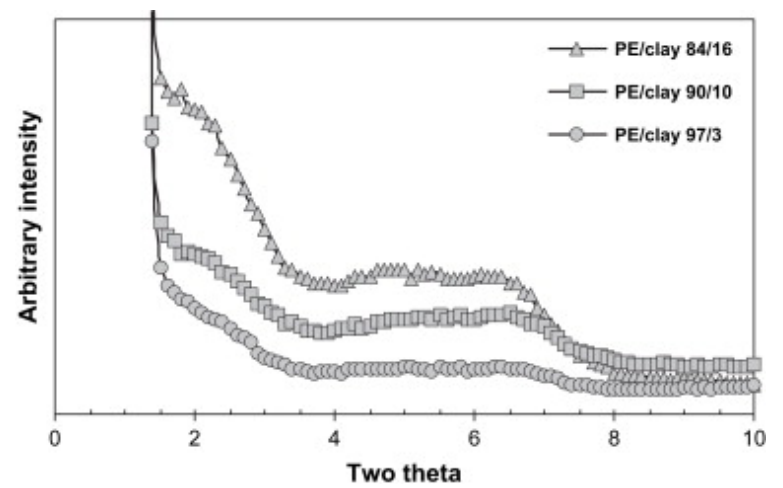

Fig. 2. XRD patterns of polyethylene clay nanocomposites.

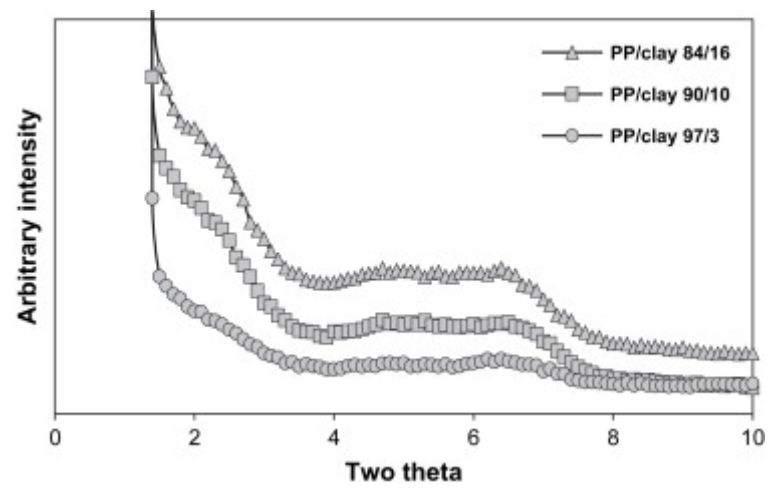

Fig. 3. XRD patterns of polypropylene clay nanocomposites.

\subsection{Transmission electron microscopy}

Transmission electron microscopy (TEM) allows for the direct imaging of the filler dispersion, albeit in a much smaller region than what is interrogated by XRD. TEM images were obtained for both PE and PP nanocomposites at 3\% inorganic clay loading, and are shown in Fig. 4, Fig. 5, respectively. The low magnification images show the presence of extended clay tactoids - in both the PE and PP - nanocomposites, indicating that the majority of the clay platelets are not well dispersed ( $c f$. delaminated or exfoliated) in either polymer matrix. The high magnification images do show intercalated structures - and much fewer immiscible formations within and around the micrometer-sized tactoids, for both PE and PP. These TEM observations are in concert with the XRD results above and, to the extent that they are representative of the composite structure, provide some further insight into the mesoscale (micrometer size) morphology of the composites. However, due to the relative large thickness of the sections imaged, the present TEM study could only qualitatively detect nanoscale structures, without enabling us to derive definitive conclusions at this length scale. Based on the combination of 
XRD and TEM, these systems contain clay which is nano-dispersed in the polymer and also clay which exists only as tactoids, i.e., some fraction of the clay is nano-dispersed.

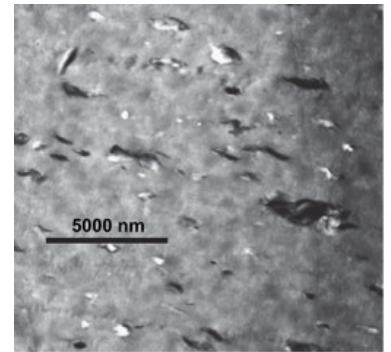

(a) low magnification

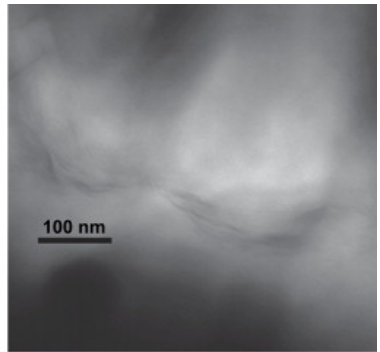

(b) high magnification

Fig. 4. TEM images of PE nanocomposites at $3 \%$ inorganic clay loading.

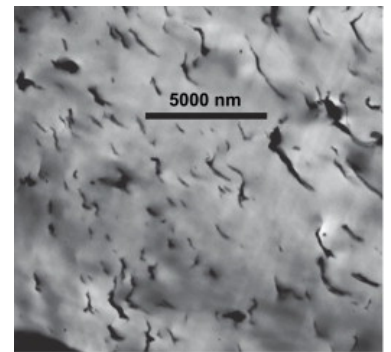

(a) low magnification

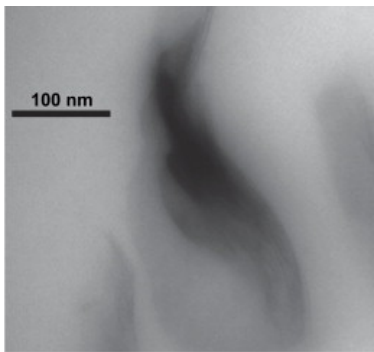

(b) high magnification

Fig. 5. TEM images of PP nanocomposites at 3\% inorganic clay loading.

\subsection{Thermogravimetric analysis}

A general limitation with organically-modified clay is the processing temperature. Normally, organicallymodified clay should be processed below $200^{\circ} \mathrm{C}$ to avoid degradation of the ammonium surfactants ${ }^{[14]}$. Previous studies have shown that the thermal stability of oligomerically-modified clay is higher than that of the common organically-modified clays. The data acquired from TGA curves include the onset of the degradation, which is usually taken as the temperature at which $10 \%$ degradation occurs, $T_{0.1}$, the mid-point temperature of the degradation, $T_{0.5}$, another measure of thermal stability, and the non-volatile residue which remains at $600{ }^{\circ} \mathrm{C}$, denoted as char. For oligomerically-modified clay, $T_{0.1}$ can reach $350{ }^{\circ} \mathrm{C}$ and $T_{0.5}$ can reach $400{ }^{\circ} \mathrm{C}[11],[11](a),[11](b),[11](c),[11](d)$. The present polymerically-modified clay also exhibits equally good thermal stability, as seen from Fig. 6 . The onset temperature is $360^{\circ} \mathrm{C}$ and mid-point temperature is $412{ }^{\circ} \mathrm{C}$. Those values are comparable to that of the oligomerically-modified clays. The non-volatile fraction that remains at $600{ }^{\circ} \mathrm{C}$ is denoted as char and contains both the polymeric char and the inorganic clay residue. From the TGA curve of the clay itself, there is $30 \%$ non-volatile remaining at $600^{\circ} \mathrm{C}$, indicating the inorganic content of the clay. An oligomerically-modified clay which contains an oligomer with a molecular weight of about 5000 also contains about $70 \%$ organic and $30 \%$ inorganic clay. In this polymerically-modified clay, if there were complete ionexchange of the inorganic cation for the polymerically-modified cation, the organic content must be substantially higher than $70 \%$, which is a clear indication that there is incomplete exchange, in agreement with the broad feature seen in the XRD traces which was assigned as indicative of incomplete ion-exchange. 


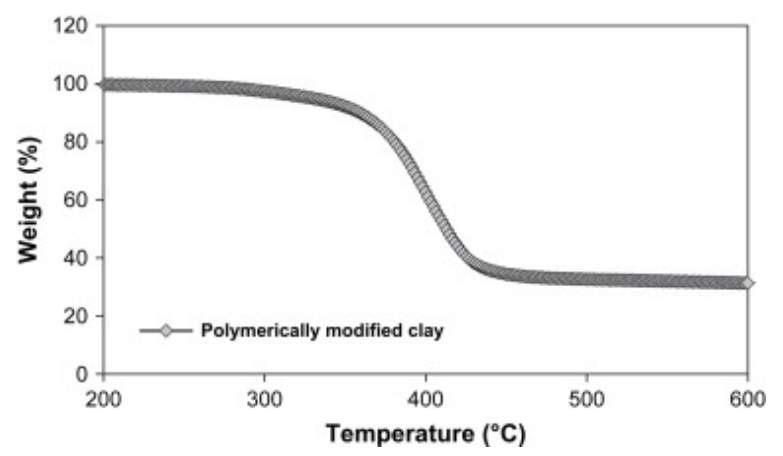

Fig. 6. TGA curve of the polymerically-modified clay.

The TGA curves for PE and PP nanocomposites are shown in Fig. 7, Fig. 8 and the corresponding data are listed in Table 2, Table 3. The temperature at $10 \%$ degradation, $T_{0.1}$, of the PE nanocomposites shows a similar trend as the PE/oligomerically-modified clay nanocomposites, a higher temperature at low clay loading and a lower temperature at high clay loading. This change is likely due to the lower thermal stability of the surfactant compared to that of the polymers. $T_{0.5}$ shows more than $10{ }^{\circ} \mathrm{C}$ enhancement at all clay loadings, while the enhancement for PE clay nanocomposites using the common organically-modified clays is less than $10^{\circ} \mathrm{C} \frac{[15]}{}$. The thermal stabilities of PP nanocomposites, in terms of the onset of degradation, are more enhanced than the PE nanocomposites; the onset temperature is $45^{\circ} \mathrm{C}$ higher for PP nanocomposites at $1 \%$ inorganic clay loading compared to unfilled PP. At higher inorganic clay loading, which means more polymeric surfactant was present in the composites, the improvement is $39^{\circ} \mathrm{C}$ for PP nanocomposite at $3 \%$ inorganic clay loading and $13^{\circ} \mathrm{C}$ at $5 \%$ inorganic clay loading. $T_{0.5}$ of the PP nanocomposites shows more than $30^{\circ} \mathrm{C}$ enhancement at all clay levels. The enhanced thermal stabilities of the PE and PP composites must be attributed to nanocomposite formation. For both PE and PP nanocomposites, the non-volatile fraction at $600{ }^{\circ} \mathrm{C}$ is equal to the amount of the inorganic clay in the system, suggesting that there is no polymeric char formed during degradation and all the PE and PP undergoe thermal degradation and volatilization.

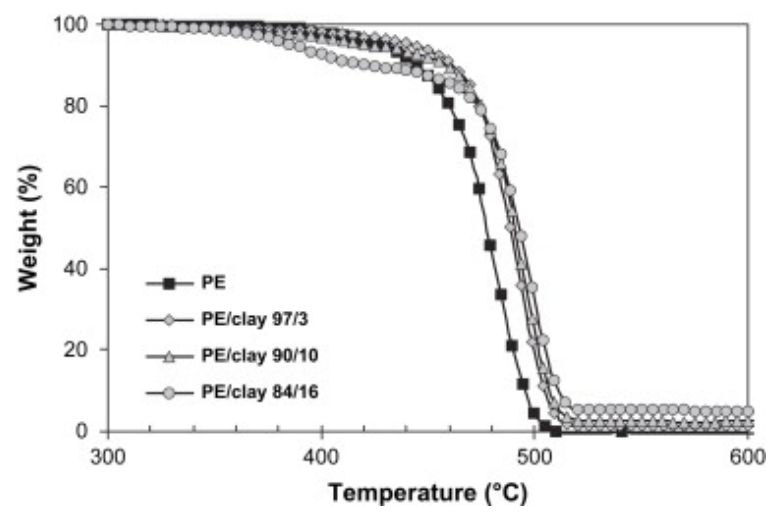

Fig. 7. TGA curves for polyethylene clay nanocomposites. 


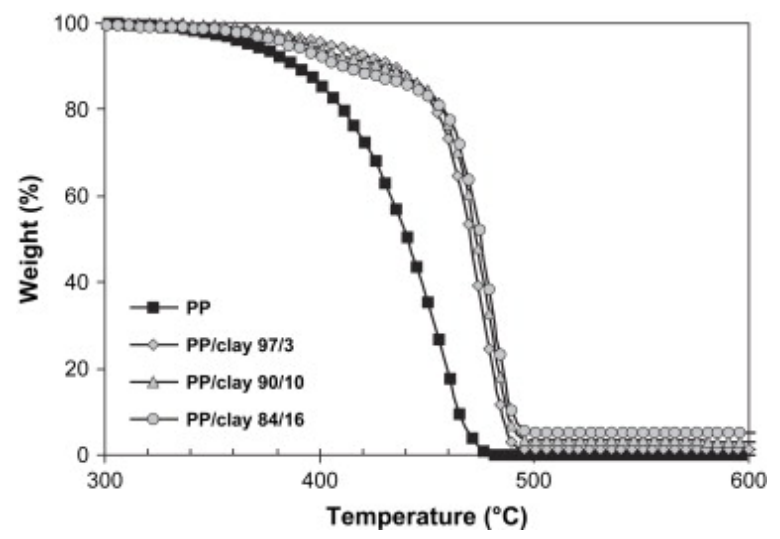

Fig. 8. TGA curves for polypropylene clay nanocomposites.

Table 2. TGA data, in nitrogen, for polyethylene and its nanocomposites

\begin{tabular}{|l|l|l|l|l|}
\hline $\mathbf{P E}, \mathbf{w t} \%$ & Polymerically-modified clay, mass $\%$ & $\boldsymbol{T}_{\mathbf{0 . 1}} \boldsymbol{~}^{\mathbf{0}} \mathbf{C}$ & $\boldsymbol{T}_{\mathbf{0 . 5}}{ }^{\mathbf{0}} \mathbf{C}$ & $\mathbf{C h a r}, \mathbf{w t} \%$ \\
\hline 100 & - & 444 & 478 & 0 \\
\hline 97 & 3 & 462 & 489 & 1 \\
\hline 90 & 10 & 457 & 491 & 2 \\
\hline 84 & 16 & 422 & 493 & 5 \\
\hline
\end{tabular}

Table 3. TGA data, in nitrogen, for polypropylene and its nanocomposites

\begin{tabular}{|l|l|l|l|l|}
\hline $\mathbf{P P}, \mathbf{w t} \%$ & Polymerically-modified clay, mass \% & $\boldsymbol{T}_{\mathbf{0 . 1}}{ }^{\mathbf{}} \mathbf{C}$ & $\boldsymbol{T}_{\mathbf{0 . 5}},{ }^{\circ} \mathbf{C}$ & Char, wt\% \\
\hline 100 & - & 389 & 440 & 0 \\
\hline 97 & 3 & 434 & 470 & 1 \\
\hline 90 & 10 & 428 & 473 & 3 \\
\hline 84 & 16 & 412 & 475 & 5 \\
\hline
\end{tabular}

\subsection{Cone calorimetry}

Cone calorimetry is the preferred method to quantify the fire performance for these systems [16]. The parameters determined from cone calorimetry include the time to ignition $\left(t_{\text {ign }}\right)$; the heat release rate, and especially its peak value (PHRR); the specific extinction area (SEA), a measure of the amount of smoke produced during the combustion; the mass loss rate (MLR); and total heat released (THR). There is a definitive structureproperty correlation between the extent of filler nano-dispersion and the PHRR reduction. There is essentially no reduction in PHRR for micro- and macro-composites, while a significant reduction is observed for genuine nanocomposites [13], [13](a), [13](b), [17]. In contrast to TEM, which provides very localized information on the $\mathrm{nm} / \mu \mathrm{m}$ structures, the evaluation of filler dispersion by cone calorimetry is based on a bulk measurement and thus it can yield a more representative, albeit indirect, picture of the nano-dispersion. Analysis of cone calorimetric data typically permits one to determine whether the clay is nano-dispersed, but is rather insensitive to the extent of dispersion, i.e., it cannot distinguish between intercalation and exfoliation/delamination.

The cone calorimetry results for the various PE and PP nanocomposites are shown in Table 4, Table 5and the heat release rate curves for the pure polymers and their nanocomposites are shown graphically in Fig. 9 , Fig. 10. PE and PP nanocomposites exhibit similar behavior at the same clay loading. The total heat released is essentially the same for both polymers and their corresponding nanocomposites. There is also no change in the time to ignition for the PP nanocomposites, compared to the unfilled PP. In the case of PE, there is a $15 \mathrm{~s}$ increase in the time to ignition for the $3 \%$ clay nanocomposites, but at higher clay loadings, the time to ignition is only slightly higher than that of unfilled PE. Time to ignition in polymer/clay nanocomposites is not wellunderstood but any increase is advantageous. The SEA is increased with increased amount of clay, which is different from our previous work $\underset{15]}{ }$. The increased amount of smoke generation probably arises from the styrene units in the surfactant. At $1 \%$ inorganic clay loading, the PHRR reduction is about $20 \%$, whereas essentially no reduction in PHRR is seen when oligomerically-modified clays are used at such low loading $\underline{\text { [11a] }}$. 
The PHRR reduction improves to $40 \%$ at $3 \%$ inorganic loadings, and becomes about $50 \%$ at $5 \%$ inorganic loading, i.e., the best reduction in PHRR was observed here for the highest clay loading. In previous studies of PE and PP nanocomposites [11], [11](a), [11](b), [11][c), [11](d), 40-60\% reduction in PHRR has been observed for nanocomposites containing $5 \%$ inorganic clay when the fillers are dispersed at the nanoscale across the polymer matrix. Thus, the nonylstyrene polymeric surfactant gives fire properties comparable to other genuine nanocomposite systems. This strong reduction in PHRR suggests that the clay is well nano-dispersed in the polymer; the conclusion from the XRD-TEM study was that both nano-dispersed and not well-dispersed clays were present (Fig. 4, Fig. 5). Cone calorimetry, a bulk measurement, suggests that there may be a larger proportion of nano-dispersed phase than can be seen from the TEM image and thus may give a better representation of the gross morphology than does TEM.

Table 4. Cone calorimeter data for polyethylene and its nanocomposites

\begin{tabular}{|c|c|c|c|c|c|c|}
\hline PE & $\begin{array}{l}\text { Polymerically-modified clay } \\
\text { (inorganic clay) }\end{array}$ & $t_{\text {ign }}(s)$ & $\begin{array}{l}\mathrm{PHRR}\left(\mathrm{kW} / \mathrm{m}^{2}, \%\right. \\
\text { reduction) }\end{array}$ & $\begin{array}{l}\text { MLR } \\
\left(\mathrm{g} / \mathrm{s} \mathrm{m}^{2}\right)\end{array}$ & $\begin{array}{l}\text { SEA } \\
\left(\mathrm{m}^{2} / \mathrm{kg}\right)\end{array}$ & $\begin{array}{l}\text { THR } \\
\left(\mathrm{MJ} / \mathrm{m}^{2}\right)\end{array}$ \\
\hline 100 & 0 & $72 \pm 3$ & $2067 \pm 154$ & $27 \pm 2$ & $350 \pm 30$ & $100 \pm 5$ \\
\hline 97 & $3(1)$ & $87 \pm 4$ & $1626 \pm 5(21)$ & $25 \pm 2$ & $421 \pm 20$ & $102 \pm 1$ \\
\hline 90 & $10(3)$ & $76 \pm 4$ & $1216 \pm 64(41)$ & $22 \pm 2$ & $501 \pm 29$ & $96 \pm 4$ \\
\hline 84 & $16(5)$ & $75 \pm 5$ & $942 \pm 58(54)$ & $17 \pm 0$ & $590 \pm 8$ & $95 \pm 2$ \\
\hline
\end{tabular}

$t_{\text {ign, }}$ time to ignition; PHRR, peak heat release rate; SEA, specific extinction area; MLR, mass loss rate; THR, total heat released.

Table 5. Cone calorimeter data for polypropylene and its nanocomposites

\begin{tabular}{|c|c|c|c|c|c|c|}
\hline PP & $\begin{array}{l}\text { Polymerically-modified clay } \\
\text { (inorganic clay) }\end{array}$ & $\begin{array}{l}t_{\text {ign, }} \\
\text { (s) }\end{array}$ & $\begin{array}{l}\text { PHRR }\left(\mathrm{kW} / \mathrm{m}^{2}, \%\right. \\
\text { reduction) }\end{array}$ & $\begin{array}{l}\text { MLR } \\
\left(\mathrm{g} / \mathrm{s} \mathrm{m}^{2}\right)\end{array}$ & $\begin{array}{l}\text { SEA } \\
\left(\mathrm{m}^{2} / \mathrm{kg}\right)\end{array}$ & $\begin{array}{l}\text { THR } \\
\left(\mathrm{MJ} / \mathrm{m}^{2}\right)\end{array}$ \\
\hline 100 & 0 & $53 \pm 1$ & $1896 \pm 62$ & $26 \pm 0$ & $482 \pm 57$ & $102 \pm 4$ \\
\hline 97 & $3(1)$ & $50 \pm 2$ & $1502 \pm 119(21)$ & $23 \pm 1$ & $574 \pm 28$ & $99 \pm 5$ \\
\hline 90 & $10(3)$ & $50 \pm 3$ & $1200 \pm 68(37)$ & $21 \pm 1$ & $656 \pm 1$ & $94 \pm 2$ \\
\hline 84 & $16(5)$ & $51 \pm 3$ & $882 \pm 74(53)$ & $17 \pm 0$ & $731 \pm 13$ & $95 \pm 4$ \\
\hline
\end{tabular}

$t_{\text {ign, }}$, time to ignition; PHRR, peak heat release rate; SEA, specific extinction area; MLR, mass loss rate; THR, total heat released.

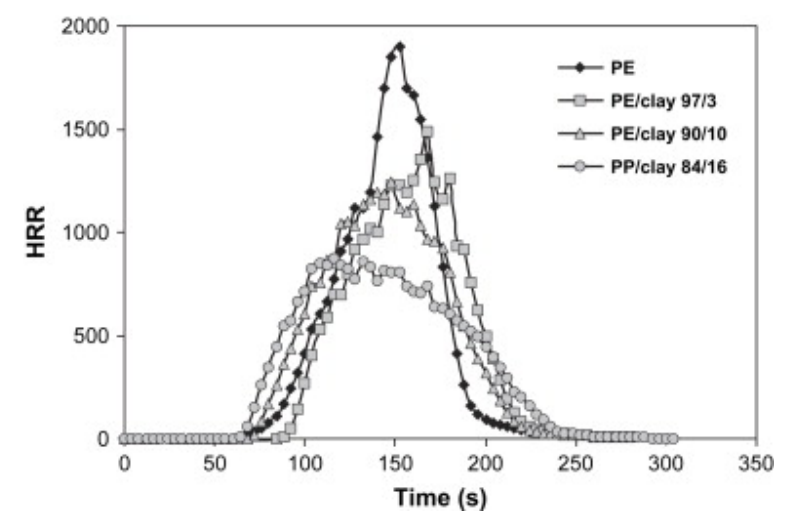

Fig. 9. Comparison of the heat release rate (HRR) plots for virgin PE and its nanocomposites at $35 \mathrm{~kW} / \mathrm{m}^{2}$ heat flux. 


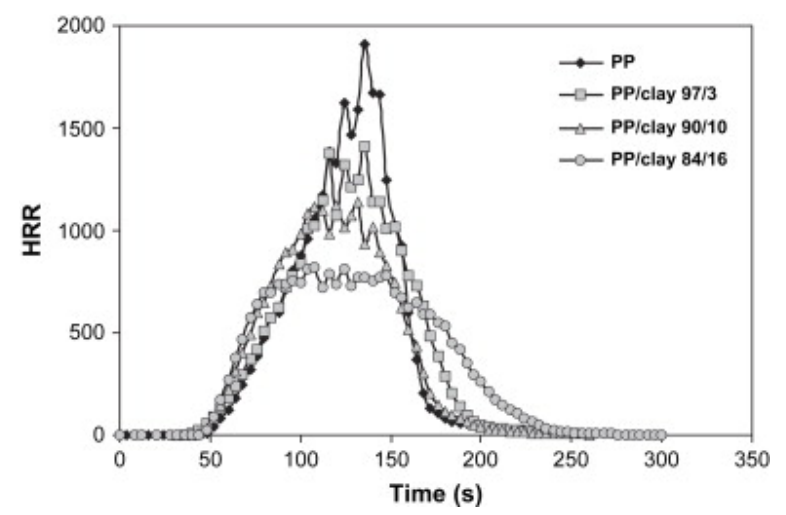

Fig. 10. Comparison of the heat release rate (HRR) plots for virgin PP and its nanocomposites at $35 \mathrm{~kW} / \mathrm{m}^{2}$ heat flux.

\subsection{Mechanical properties}

Most PE and PP nanocomposites based on oligomerically-modified clays show decreased Young's modulus and tensile strength, along with a small decrease in elongation at break. The Young's modulus and tensile strength of the nanocomposites could, in principle, be improved by increasing the inorganic clay content, but this would also lead to a poorer clay dispersion, which would decrease the PHRR reduction and hence the fire performance. The tensile mechanical properties of the present nanocomposites are presented in Table $\underline{6}$, Table 7. For both PE and PP nanocomposites, the tensile strength and Young's modulus are slightly decreased compared to the respective unfilled polymers, which suggest that a plasticizing effect may arise due to the nonyl units attached to the styrene. To diminish the plasticizing effect, the inorganic clay content has to be increased

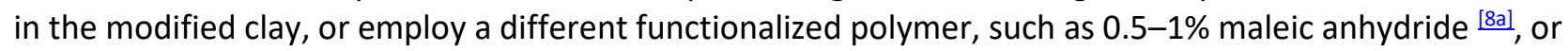
ammonium end-terminated polymer [18], [18](a), [18](b). For PE nanocomposites, the elongation shows a small decrease from $450 \%$ to $390 \%$ when the inorganic clay loading increases from $0 \%$ to $5 \%$. For PP nanocomposites, the elongation increases from $380 \%$ to $500 \%$ when inorganic clay loading increases to $3 \%$. This latter behavior is qualitatively different from that of PP nanocomposites containing montmorillonite clays with most other surfactants $\frac{[8 a]}{\text {. }}$

Table 6. Tensile properties of PE and its nanocomposites

\begin{tabular}{|l|l|l|l|l|}
\hline PE & Inorganic clay & Tensile strength (MPa) & Modulus (MPa) & Elongation (\%) \\
\hline 100 & 0 & $14 \pm 2$ & $240 \pm 16$ & $457 \pm 29$ \\
\hline 97 & 1 & $14 \pm 3$ & $210 \pm 8$ & $480 \pm 22$ \\
\hline 90 & 3 & $13 \pm 3$ & $205 \pm 9$ & $455 \pm 35$ \\
\hline 84 & 5 & $10 \pm 2$ & $190 \pm 11$ & $390 \pm 12$ \\
\hline
\end{tabular}

Table 7. Tensile properties of PP and its nanocomposites

\begin{tabular}{|l|l|l|l|l|}
\hline PP & Inorganic clay & Tensile strength (MPa) & Modulus (MPa) & Elongation (\%) \\
\hline 100 & 0 & $34 \pm 5$ & $1041 \pm 58$ & $378 \pm 20$ \\
\hline 97 & 1 & $31 \pm 2$ & $1055 \pm 40$ & $380 \pm 36$ \\
\hline 90 & 3 & $34 \pm 6$ & $880 \pm 23$ & $500 \pm 19$ \\
\hline 84 & 5 & $26 \pm 1$ & $832 \pm 31$ & $450 \pm 12$ \\
\hline
\end{tabular}

\section{Conclusions}

A polymeric surfactant, in the form of a copolymer containing 4-nonylstyrene and vinylbenzyl triethylammonium chloride, was synthesized. When this polymer was used to exchange the sodium cations of montmorillonite clays, a non-uniform structure was observed for the polymerically-modified clays, which was tentatively attributed to the high molecular weight $(31,000)$ of the surfactant. PE and PP nanocomposites were fabricated through melt-blending with the polymerically-modified clay. XRD and TEM indicated a mixed 
morphology that was mainly intercalated with some immiscible content. Nanocomposites containing $5 \%$ inorganic content exhibited a 50\% reduction in PHRR according to cone calorimetry, which strongly suggests that true nanocomposites have been formed. A plasticizing effect of the modified clay on the PE and PP matrices is present, albeit to a smaller extent compared to oligomerically-modified clays studied previously. For the PP nanocomposites the elongation at break is improved compared to the unfilled polymer, a behavior which has not been observed with other modified clays.

\section{Acknowledgement}

The assistance of E. Manias and M.J. Heidecker in obtaining the transmission electron microscopy images and in helpful discussion is appreciated and acknowledged.

\section{References}

[1] M. Alexandre, P. Dubois. Polymer-layered silicate nanocomposites: preparation, properties and uses of a new class of materials. Mater Sci Eng, R28 (2000), pp. 1-63

[2] (a) E.P. Giannelis, R. Krishnamoorti, E. Manias. Polymer-silicate nanocomposites: model systems for confined polymers and polymer brushes. Adv Polym Sci, 138 (1998), pp. 107-148. (b) E.P. Giannelis. Polymer layered silicate nanocomposites. Adv Mater, 8 (1996), pp. 29-35

[3] S. Sinha Ray, M. Okamoto. Polymer/layered silicate nanocomposites: a review from preparation to processing. Prog Polym Sci, 28 (2003), pp. 1539-1641

[4] M. Zanetti, G. Camino, D. Canavese, A.B. Morgan, F.J. Lamelas, C.A. Wilkie. Fire retardant halogen-antimonyclay synergism in polypropylene layered silicate nanocomposites. Chem Mater, 14 (2002), pp. 189-193

[5] J. Zhu, P. Start, K.A. Mauritz, C.A. Wilkie. Thermal stability and flame retardancy of poly(methyl methacrylate)-clay nanocomposites. Polym Degrad Stab, 77 (2002), pp. 253-258

[6] S. Zhang, A.R. Horrocks. A review of flame retardant polypropylene fibres. Prog Polym Sci, 28 (2003), pp. 1517-1538

[7] G. Beyer. Flame retardant properties of EVA-nanocomposites and improvements by combination of nanofillers with aluminum trihydrate. Fire Mater, 25 (2001), pp. 193-197

[8] (a) E. Manias, A. Touny, L. Wu, K. Strawhecker, B. Lu, T.C. Chung. Polypropylene/montmorillonite nanocomposites: a review of synthetic routes and materials properties. Chem Mater, 13 (2001), pp. 3516-3523. (b) K.H. Wang, M.H. Choi, C.M. Koo, Y.S. Choi, I.J. Chung. Synthesis and characterization of maleated polyethylene/clay nanocomposites. Polymer, 42 (2001), pp. 9819-9826

[9] K.H. Wang, I.J. Chung, M.C. Jang, J.K. Keum, H.H. Song. Deformation behavior of polyethylene/silicate nanocomposites as studied by real-time wide-angle X-ray scattering. Macromolecules, 35 (2002), pp. 5529-5535

[10] (a) S. Su, D.D. Jiang, C.A. Wilkie. Novel polymerically-modified clays permit the preparation of intercalated and exfoliated nanocomposites of styrene and its copolymers by melt blending. Polym Degrad Stab, 83 (2004), pp. 333-346. (b) S. Su, D.D. Jiang, C.A. Wilkie. Study on the thermal stability of polystyryl surfactants and their modified clay nanocomposites. Polym Degrad Stab, 84 (2004), pp. 269277. (c) S. Su, D.D. Jiang, C.A. Wilkie. Polybutadiene-modified clay and its nanocomposites. Polym Degrad Stab, 84 (2004), pp. 279-288

[11] (a) J. Zhang, D.D. Jiang, C.A. Wilkie. Polyethylene and polypropylene nanocomposites based upon an oligomerically modified clay. Thermochim Acta, 430 (2005), pp. 107-113. (b) Jinguo Zhang, D.D. Jiang, C.A. Wilkie. Thermal and flame properties of polyethylene and polypropylene nanocomposites based on an oligomerically-modified clay. Polym Degrad Stab, 91 (2006), pp. 298-304. (c) J. Zhang, D.D. Jiang, C.A. Wilkie. Fire properties of styrenic polymer-clay nanocomposites based on an oligomerically-modified clay. Polym Degrad Stab, 91 (2006), pp. 358-366. (d) J. Zhang, D.D. Jiang, C.A. Wilkie Polyethylene and polypropylene nanocomposites based on a three component oligomerically-modified clay. Polym Degrad Stab, 91 (2006), pp. 641-648

[12] B.N. Jang, D. Wang, C.A. Wilkie. Macromolecules, 38 (2005), pp. 6533-6543 
[13] (a) J.W. Gilman, T. Kashiwagi, M. Nyden, J.E.T. Brown, C.L. Jackson, S. Lomakin, et al. Flammability studies of polymer layered silicate nanocomposites: polyolefin, epoxy, and vinyl ester resins. S. AlMaliaka, A. Golovoy, C.A. Wilkie (Eds.), Chemistry and technology of polymer additives, Blackwell Scientific, London (1998), pp. 249-265. (b)

J.W. Gilman, C.L. Jackson, A.B. Morgan, E. Manias, E.P. Giannelis, M. Wuthenow, et al .Flammability properties of polymer/layered-silicate nanocomposites. polypropylene and polystyrene nanocomposites. Chem Mater, 12 (2000), pp. 1866-1873

[14] J. Zhu, F.M. Uhl, A.B. Morgan, C.A. Wilkie. Studies on the mechanism by which the formation of nanocomposites enhances thermal stability. Chem Mater, 13 (2001), pp. 4649-4654

[15] J. Zhang, C.A. Wilkie. Preparation and flammability properties of polyethylene-clay nanocomposites. Polym Degrad Stab, 80 (2003), pp. 163-169

[16] B. Schartel, M. Bartholmai, U. Knoll. Some comments on the use of cone calorimeter data. Polym Degrad Stab, 88 (2005), pp. 540-547

[17] C.A. Wilkie, X. Zheng, G. Chigwada, M. Costache, B.N. Jang, J. Zhang. A review of recent work on fire retardancy of nanocomposites. C.A. Wilkie, G.L. Nelson (Eds.), Fire and polymers IV: materials and concepts for hazard prevention, Oxford University Press (2006), pp. 8-20.

X. Zheng, D.D. Jiang, C.A. Wilkie. Methyl methacrylate oligomerically-modified clay and its poly(methyl methacrylate) nanocomposites. Thermochim Acta, 435 (2005), pp. 202-208.

G. Chigwada, D.D. Jiang, C.A. Wilkie. Polystyrene nanocomposites based on carbazole-containing surfactants. Thermochim Acta, 436 (2005), pp. 113-121. X. Zheng, D.D. Jiang, C.A. Wilkie. Polystyrene nanocomposites based on an oligomerically-modified clay containing maleic anhydride. Polym Degrad Stab, 91 (2006), pp. 108-113

[18] (a) Z.M. Wang, H. Nakajima, E. Manias, T.C. Chung. Exfoliated PP/clay nanocomposites using ammoniumterminated PP as the organic modification for montmorillonite. Macromolecules, 36 (2003), pp. 89198922. (b)Wang, ZM. Synthesis of functional PP and PVDF and application in nanocomposites, Ph.D. thesis, Penn State University; 2005. 